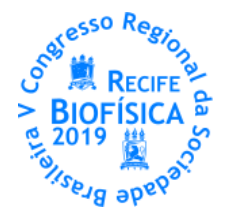

\title{
MODELAGEM DO SISTEMA INTRAOCULAR DE CONVECÇÃO FORÇADA
}

\author{
Humberto Dória Silva ${ }^{1 *}$, Eduardo Dória Silva ${ }^{1}$, Maria Tamires Dória Silva², Cristiane Pereira Dória ${ }^{2}$ \\ ${ }^{1}$ UFPE; ${ }^{2}$ Profissional liberal \\ *hdoria@ufpe.br
}

\begin{abstract}
INTRODUÇÃO
Em 2011 foi criado o grupo de pesquisa "Transferência de massa em meio poroso flexível", com o objetivo de pesquisar o mecanismo de transferência de massa, por convecção forçada, nos materiais orgânicos, para fortalecer o trabalho analítico de recuperação física da visão humana, que estava sendo desenvolvido, pelo primeiro autor deste trabalho, desde o ano de 1998, inicialmente, para suprir as necessidades pessoais.
\end{abstract}

Nesta publicação tem o objetivo de mostrar um modelo esquemático da convecção forçada, que represente o sistema de transferência de massa intraocular, para debater a nova abordagem, já discutida em vários congressos especializados e demostrada em diversas publicações, porém, sem nenhum modelo esquemático.

O olho humano é o órgão do sentido da visão, que tem a função de produzir e enviar para o cérebro, em estímulos nervosos, a imagem projetada na retina, através dos raios luminosos, incidentes na córnea, e, selecionados pelo processo físico de inversão da imagem. Para manter viva, as células intraoculares, é necessária a entrada de nutrientes e oxigênio que, em consequência, produz resíduos metabólico e gás carbónico. Nesta abordagem, o modelo do biorreator transforma a entrada, os nutrientes e o oxigênio, nos rejeitos, (os resíduos metabólicos) e gás carbônico, na saída, para enfatizar o processo de transferência da massa móvel, por convecção forçada, (Silva H. D., id. 2012b, id., id. 2013a, id. 2013c, id. 2013d).

A esponja produzida em poliéster e poliuretano, usada em limpeza de objetos domésticos é um meio poroso flexível. A córnea, cristalino e a retina são modeladas como meios porosos flexíveis, e a íris com um diafragma de uma válvula direcional (Silva H. D., et al. 2018).

\section{MATERIAIS E MÉTODOS}

A equipe realizou estudo bibliográfico dos sintomas descritos nas entrevistas realizadas com diversos amigos e colegas, além das percepções do primeiro autor, durante o período de recuperação de sua visão. Não há necessidade do parecer do comitê de ética, porque não foi necessário qualquer procedimento invasivo e os exercícios foram realizados sob a responsabilidade da própria pessoa.

Elementos abordados no modelo esquemático

Lágrima - Secreção límpida, incolor e salgada, produzida pelas glândulas lacrimais, localizada na borda súpero-externa da órbita. A lágrima limpa e umidifica a conjuntiva e a córnea, além de nutrir o epitélio corneano e servir como meio de transporte de resíduos metabólicos e $\mathrm{CO}_{2}$, que são drenados pelos canais lacrimais.

Humor aquoso - Líquido incolor, transparente, de consistência aquosa, produzido no pars plicata do corpo ciliar, (produzido na câmara posterior), preenche as câmaras oculares e drenado da região trabecular para canal de Schlemm, na câmara anterior. Sua principal função é nutrir o estroma corneano e o cristalino, além de regular a pressão interna do olho e servir como meio de transporte de resíduos metabólicos e $\mathrm{CO}_{2}$.

Nutrição da retina - Os nutrientes, oxigênio, resíduos metabólicos e dióxido de carbono são passados da coroide, camada ricamente vascularizada, para a retina através da membrana de Bruch. 0 fluido de entrada serve como meio de transporte de todos os compostos.

Córnea - No modelo esquemático, Figura 1, está mostrado três regiões transparentes, que são suficientes para explicar a transferência de massa, no epitélio corneano, na membrana de Bowman e no estroma (incluindo a membrana de Descemet e endotélio). A membrana de Bowman está representada por uma superfície flexível e impermeável, entre as duas outras regiões. Estas duas regiões estão esquematizadas como meios porosos flexíveis. A região anterior representa aproximadamente $10 \%$ da espessura da córnea enquanto a posterior representa aproximadamente $90 \%$.

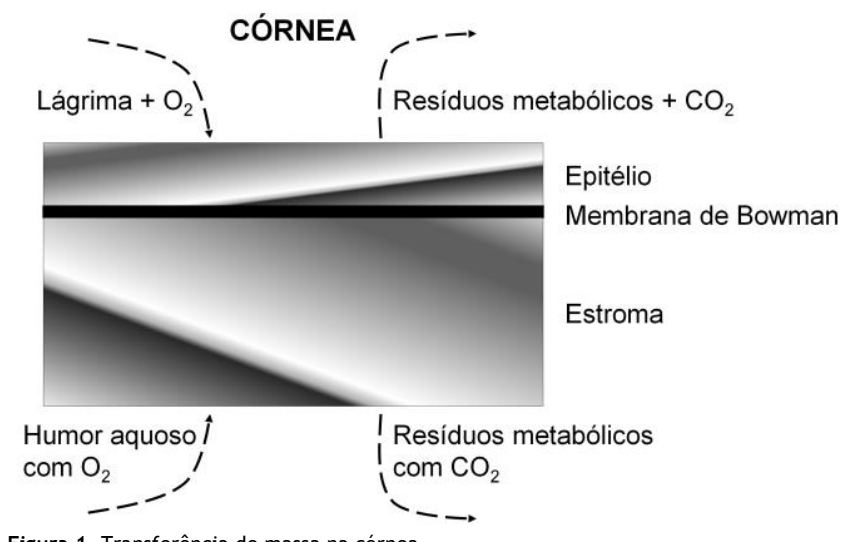

Figura 1. Transferência de massa na córnea.

Tração do movimento de convecção forçada da córnea - Os movimentos dos músculos oblíquos superiores, flexionam as córneas, (Silva H. D., et al. 2011), no processo de acomodação da córnea, para as fusões das imagens projetadas nas duas retinas. A flexão da córnea provoca a compressão (contração do músculo oblíquo superior) ou expansão (extensão do músculo oblíquo superior) dos espaços entre as diversas camadas, tanto no epitélio quanto no estroma. Este movimento físico, de compressão e expansão, está representado pelo êmbolo, Figura 2. Para simplificar, a curvatura da córnea não foi esquematizada.

Iris - A íris apresenta a cor do olho e em seu centro existe um orifício, a pupila, por onde passa a luz que penetra no olho. Pela pupila passa o humor aquoso, no sentido, câmara posterior para a câmara anterior. 0 humor aquoso é produzido na câmara posterior 
e, como mostra a Figura 3, chega a pupila através do espaço entre a íris e o cristalino, dependendo da diferença de pressão entre as câmaras. Se a pressão na câmara posterior for maior do que a pressão na câmara anterior o fluxo do humor aquoso passa, caso contrário é interrompido, porque a íris atua como diafragma, para não contaminar a composição nutricional na câmara posterior.

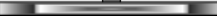

Figura 2. Êmbolo para realizar a transferência de massa intraocular.

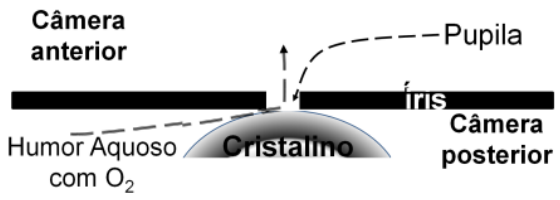

Figura 3. Transferência de massa da câmara posterior para a câmara anterior.

Cristalino - É uma lente biconvexa, incolor, com aparência gelatinosa e grande elasticidade, situada entre a íris e o humor vítreo. Os músculos ciliares fazem a acomodação, aumentando ou reduzindo a curvatura do cristalino. 0 cristalino tem a função de focalizar a imagem na retina e é alimentado pelo humor aquoso contido na câmara posterior onde drena os resíduos metabólicos. No esquema, na Figura 4, o cristalino é mostrado como um meio poroso flexível, em forma elipsoidal, possuindo a entrada dos nutrientes $\mathrm{e}_{2}$ e um dreno para saída dos resíduos metabólicos e $\mathrm{CO}_{2}$.

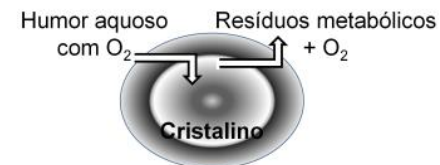

Figura 4. Transferência de massa da câmara posterior para a câmara anterior.

Tração do movimento de convecção forçada do cristalino - As setas mostram o sentido de variação do sistema. A contração aumenta a curvatura e a expansão reduz a curvatura do modelo do esquema. A rede que circunda o cristalino é mostrada na Figura 5.

Figura 5. Modelo do corpo ciliar (perfil)

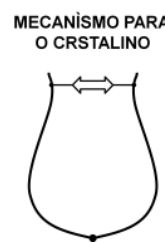

Humor vítreo - É uma substância gelatinosa e viscosa que está ente o cristalino e a retina. Ele tem a função mecânica de transmitir a variação de pressão para a retina, causada pela variação da curvatura da córnea e manter o formato do olho, (Silva H. D., et al. 2013b). A transferência de massa é muito lenta em relação a transferência de massa abordada neste trabalho, logo pode ser considerado um meio flexível sem poros.

Retina - Membrana nervosa do seguimento posterior do olho, não vascularizada, com dez camadas, ligada ao cérebro através do nervo óptico. Na retina é projetada a imagem a ser discretizada através dos seus fotorreceptores, que fazem a transdução em sinais elétricos e os envia para o cérebro. 0 transporte de massa por convecção forçada é realizado pela variação da força motora da compressão da esclera contra o humor vítreo e da variação de pressão intraocular, (Silva H. D., et al. 2013b), ambos, causados pelo processo de fusão de imagens, (flexão da córnea, ação do músculo oblíquo superior). No modelo é representado por um meio poroso flexível, Figura 6 sem a representação da compressão da esclera, para simplificar o diagrama.

\section{RESULTADOS E DISCUSSÃO}

A Figura 6 mostra o diagrama completo, para mostrar o processo de transferência de massa intraocular por convecção forçada. 0 sistema tem três entradas de alimentação dos nutrientes e oxigênio, e tem três sumidouros.

Lágrima - Entra através da superfície externa e a penetração é facilitada pela redução da curvatura da córnea (expansão do espaço entre camadas) conforme a direção e distância do alvo observado. O movimento para aumento da curvatura da córnea (compressão do espaço entre camadas) ocorre a expulsão da massa móvel. A frequente oscilação de mudança de estado, a expansão e compressão, é o processo de agitação da massa móvel que produz a uniformização da concentração e viscosidade da massa de transporte para eliminação dos resíduos metabólicos e $\mathrm{CO}_{2}$. 0 movimento de subir e descer o êmbolo, na Figura 6 corresponde ao movimento descrito em relação a variação da curvatura da córnea. Se o êmbolo ficar sendo movimentando, por muito tempo, inclinado, haverá regiões em que a massa móvel ficará com diferentes concentrações e viscosidade e prejudica o processo de eliminação dos resíduos metabólicos e do $\mathrm{CO}_{2}$. Se após este período inclinado, o êmbolo for colocado na posição correta, não será possível eliminar os resíduos metabólicos, em muitas regiões do meio poroso flexível, sem ações específicas, assim como ocorre com a córnea, em relação as ações em períodos prolongados ou frequentes do uso da visão com problemas de refração. Os hábitos podem ser determinantes para as diferenças de erro de refração entre as pessoas. A Ceratoscopia Computadorizada, também chamado de Topografia da Córnea, é o exame que mostra, ponto a ponto, as variações da curvatura corneana provocadas pelo acúmulo de resíduo no epitélio. O epitélio elimina a massa metabólica acumulando nas laterais da fenda palpebral ou através dos canais lacrimais para as fossas nasais.

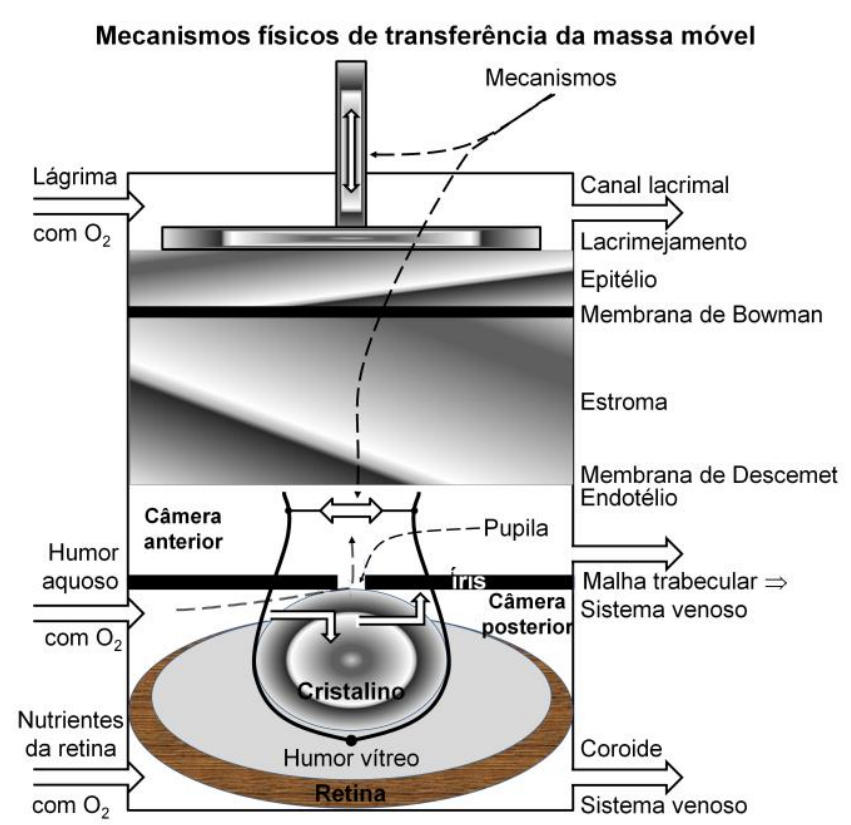

Figura 6. Modelo do mecanismo de transferência de massa do biorreator intraocular (cilíndrico). 
Humor aquoso (na córnea) - Por causa da localização, (posterior à membrana de Bowman), da estrutura e da espessura do estroma, a penetração e expulsão ocorrem em situações opostas às descritas, em relação à lágrima, são movimentos antagônicos. A penetração da massa móvel é facilitada pelo aumento da curvatura da córnea (expansão do espaço central entre camadas) conforme a direção e distância do alvo observado. A expulsão da massa móvel ocorre com a redução da curvatura da córnea (compressão do espaço central entre camadas). A frequente oscilação de mudança de estado, a expansão e compressão, é o processo de agitação da massa móvel que produz a uniformização da concentração e viscosidade da massa de transporte para eliminação dos resíduos metabólicos e $\mathrm{CO}_{2}$. $\mathrm{O}$ modelo do esquema apresentado na Figura 6 não representa o efeito da curvatura da córnea no processo. No olho humano, a delimitação da córnea com a esclera é, neste trabalho, admitida como cilíndrica para facilitar a exposição, então no para aumentar da curvatura da córnea, o músculo oblíquo superior contrai no sentido de redução do diâmetro do cilindro delimitador, mas, pode resultar em cônico, após o relaxamento devido a viscosidade dos resíduos. A genética e os hábitos pessoais resultam na forma de acúmulo dos resíduos metabólicos intra corneano, que pode causar ceratocone, (base cônica anterior), ou redução angular da câmara anterior (base cônica posterior). A desidratação do resíduo metabólico acumulado pode ser aglomerado em partículas que refratam em projeções na retina, causando os sintomas da miopia, hipermetropia, astigmatismo e moscas volantes, entre outros. Em 1619, Scheiner, (apud Werner L., et al. 2000), um astrônomo e jesuíta alemão, em seu experimento observou, pela primeira vez o que, neste trabalho, está identificado como lentes intraoculares formadas pela aglutinação de resíduos, (Silva H. D., et al. 2012a). A nictalopia (cegueira noturna) causada pela opacidade do resíduo metabólico espalhado na córnea que absorve uma parte da energia luminosa que chega a córnea, (Silva H. D., et al. 2013a). O aumento da pressão intraocular está identificado como depósitos na malha trabecular, das aglutinações formadas e liberadas pelo estroma. Estes depósitos aumentam a resistência de passagem da massa móvel para a corrente sanguínea.

Humor aquoso (no cristalino) - A penetração é facilitada pela redução da curvatura do cristalino (expansão do espaço entre camadas) conforme distância do alvo observado. 0 movimento para aumento da curvatura do cristalino (compressão do espaço entre camadas) ocorre a expulsão da massa móvel. A frequente oscilação de mudança de estado, a expansão e compressão, é o processo de agitação da massa móvel que produz a uniformização da concentração e viscosidade da massa de transporte para eliminação dos resíduos metabólicos e $\mathrm{CO}_{2}$. O cristalino é apresentado na Figura 6 como meio poroso flexível e a contração e expansão foram descritos em "tração do movimento de convecção forçada do cristalino". Assim como na córnea, se o cristalino mantiver por muito tempo, a mesma acomodação, haverá regiões em que a massa móvel ficará com diferentes concentrações e viscosidade metabólicas prejudica o processo de eliminação dos resíduos metabólicos e do $\mathrm{CO}_{2}$. Para eliminar, os resíduos metabólicos destas regiões, são necessários movimentos específicos com ações prolongadas ou frequentes. A genética e os hábitos pessoais resultam na forma de acúmulo dos resíduos metabólicos no cristalino, que pode causar miopia, hipermetropia, astigmatismo e moscas volantes, entre outros. A desidratação do resíduo metabólico acumulado pode ser aglomerado em partículas que refratam em projeções na retina, causando os sintomas da miopia, astigmatismo e moscas volantes, entre outros. Por tratar de acúmulo de resíduos metabólicos, em um sistema com reduzido transporte de massa, o cristalino pode aumentar seu volume e consequentemente enrijecer, adquirir a cor amarelado, inerente a cor do resíduo metabólico, chegando até a completa opacidade, denominada catarata, (Silva H. D., et al. 2018).

Nutrientes da retina - Como já escrito, a força motriz do transporte de massa por convecção forçada é o mesmo usado na córnea, o músculo oblíquo superior. A extensão do músculo oblíquo superior expande o volume da retina e facilita a penetração dos nutrientes na córnea enquanto que a contração do músculo oblíquo superior comprime a retina expulsando a massa móvel. 0 acúmulo de resíduo na retina enrijece, (perda da elasticidade), prejudica a circulação na massa móvel e pode causar algumas patologias:

Pós imagem negativa e adaptação ao escuro devido a redução do tempo de resposta, (dificuldade na nutrição);

Retinose pigmentar (provavelmente) e degeneração macular (Silva H. D., et al. 2013d) devido à falta de circulação da massa móvel, devido a rigidez;

Ruptura da retina devido a perda da elasticidade e não suporta os movimentos de expansão e compressão.

Associação da idade à patologia - As patologias associadas ao acúmulo de resíduos metabólicos não devem ser adotadas com ligação à idade. Para uma série temporal ser ligada a idade é necessário ter o mesmo sinal, positivo ou negativo, ou seja, tem que satisfazer à expressão 1 , o resultado da expressão ser verdadeiro. Um exemplo muito conhecido é a indicação da idade de uma árvore através dos anéis de crescimento, o número de pares de anéis corresponde à idade da árvore.

$$
f(t)=|f(t)| \text { ou } f(t)=-|f(t)|
$$

\section{CONCLUSÕES}

Está mostrado, através de um diagrama simplificado, que a falha no transporte de massa intraocular por convecção forçada é a causadora do maior quantitativo de patologias oculares. A idade e a patologia estão ligadas pelo tempo de convivência do problema, antes de encontrar uma solução definitiva para o problema.

É necessário investir na prevenção. Para iniciar uma atividade física, o atleta faz alguns exercícios, e para manter-se exercendo a atividade o atleta faz o preparo físico. A visão é um dos cinco sentidos humanos, mas necessita da habilidade física dos olhos para a sua percepção, porém, nenhum preparo físico é adotado para o uso dos olhos. É necessário realizar exercícios físicos para manter com excelente preparo físico o sistema motor intraocular de convecção forçada e o sistema motor depende da imagem que chega ao cérebro

\section{AGRADECIMENTOS}

Em primeiro lugar a Deus, por ter ajudado o primeiro autor nos longos anos de sofrimentos, causados pelo médico, que recomendou a viagem de avião sua mãe, 15 dias antes do nascimento do paciente, que o levou a ser um analítico observador dos eventos em seu próprio corpo. Em adição, por ajudar a todos coexistir, durante os danos causa dos pelas decisões políticas e econômicas do país. Ao Marcos, irmão dos dois primeiros autores, que, em 1999, mostrou a importância do relaxamento oculomotor para o tratamento da vista, em um livro de autoajuda. Aos colegas, dos dois primeiros autores, membros do ANDES-SN Sindicato Nacional e, também, aos colegas membros da Seção Sindical ADUFEPE, que, durante os intervalos dos encontros sindicais, proveu importantes ajudas científicas para a pesquisa. A todos os amigos, colegas e membros da família entrevistados que contribuíram direta ou indiretamente para pesquisa. Nenhuma instituição pública ou privada participou com ajuda financeira, para a publicação deste trabalho. Todos os autores concordam com os agradecimentos. 


\section{REFERÊNCIAS}

Silva H. D., et al., Error! Reference source not found., Journal Defect and Diffusion Forum VI, abril 2011, http://www.scientific.net/DDF.312-315.737. Id., Simulation of the Errors of Refraction in the Human Eye,

Capítulo 15, Öchsner, A., da Silva, L. F. M., Altenbach, H., Livro Analysis and Design of Biological Materials and Structures, Springer Berlin Heidelberg, 2012a,14:187-200.

In., Error! Reference source not found., Journal Defect and Diffusion Forum VII, abril 2012b, http://www.scientific.net/DDF.326-328.18.

Id., Error! Reference source not found., Capítulo 16 do livro Characterization and Development of Biosystems and Biomaterials, V. 29. pp. 217-226, Springer, janeiro 2013a, http://www.springer.com/978-3-642-31469-8.

Id., Simulation of Variation of Intraocular Pressure, Capítulo 18 do livro Characterization and Development of Biosystems and Biomaterials, V. 29. pp. 235-253, Springer, janeiro 2013b, http://www.springer.com/978-3-642-31469-8.

Id, Error! Reference source not found., Journal Defect and Diffusion Forum VIII, fevereiro 2013c, WWW.scientific.net/DDF. 334-335.225.

Id., Error! Reference source not found., Journal Defect and Diffusion Forum VIII, fevereiro 2013d, WWW.scientific.net/DDF. 334-335.230.

Id., Analysis of the Disturbances Caused by Intraocular Forced Convection Mechanism Failure, Capítulo 3, Zilfyan A., Livro, Difficulties in Cataract Surgery, IntechOpen, Londres, 2018, 3:4564.

Werner L., et al., Physiology of accommodation and presbyopia, Arq Bras Oftalmol, 2000, 63:503-506. 